Artículo recibido:

21 de enero del 2012.

Evaluado:

19 de marzo del 2012.

Aceptado:

4 de mayo del 2012.

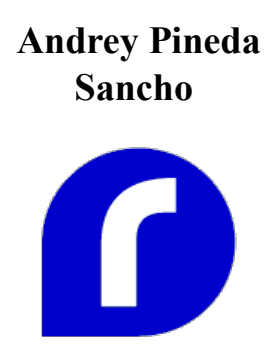

Dagoberto Núñez Picado

\section{La participación del Instituto Centroamericano de Extensión de la Cultura (ICECU) en el campo religioso mesoamericano}

Resumen

Este artículo expone los resultados de un análisis de contenido aplicado a las respuestas brindadas por el Instituto Centroamericano de Extensión de la Cultura (ICECU) a preguntas sobre magia y brujería efectuadas por su audiencia a través de un intercambio epistolar con la institución. Este análisis, realizado a la luz de la teoría del campo religioso de Pierre Bourdieu, muestra la visión del Instituto respecto de las prácticas y creencias mágicas, así como su posicionamiento dentro del campo religioso mesoamericano. Presenta también los principales rasgos de la labor del Instituto, en tanto institución educativa/cultural dentro de la región, así como el proceso que le llevó a incursionar en el campo religioso mesoamericano.

Palabras Clave

Campo religioso, religión, magia y brujería, relación comunicativa, acción pedagógica, violencia simbólica, diversidad cultural

\section{The Participation of Instituto Centroamericano de Extensión de la Cultura (ICECU) in the Mesoamerican Religious Field}

AbSTRAct

This paper shows the results of a content analysis on magic and witchcraft in accordance with answers provided by the Instituto Centroamericano de Extensión de la Cultura (ICECU). The analysis was based on the answers which arouse out of an exchange of letters between the institution and its audience. Based on the theory of the Religious Field by Pierre Bourdieu, the paper shows the outlook of the institution about magic practices and beliefs, as well as how it fits within the Mesoamerican Religious Field. The main traits of the institute's work, as an educational and cultural institution in the region, and the processes that led it to participate in the Mesoamerican religious field are also presented.

KEY WORDS

Religious field, religious, magic and witchcraft, communicative relation, pedagogic action, symbolic violence, cultural diversity

Andrey Pineda y Dagoberto Núñez son investigadores de Procesos Emergentes de Prácticas Religiosas Contemporáneas del Programa de Globalización, Cultura y Desarrollo (PROGLOCDE) del Centro de Investigaciones en Cultura y Desarrollo (CICDE). Correos electrónicos: Andrey Pineda Sancho apineda@uned.ac.cr; Dagoberto Nuñez Picado dnunez@uned.ac.cr. 


\section{La participación del Instituto Centroamericano de Extensión de la Cultura (ICECU) en el campo religioso mesoamericano}

\section{Introducción}

El presente artículo es resultado parcial de un proyecto mayor de investigación que analiza las percepciones y conceptualizaciones sobre Dios en Centroamérica a través de la correspondencia del Instituto Centroamericano de Extensión de la Cultura (ICECU). Dicho proyecto es desarrollado desde el seno del Centro de Investigación en Cultura y Desarrollo (CICDE) de la Vicerrectoría de Investigación de la Universidad Estatal a Distancia (UNED). La investigación tiene como finalidad desentrañar las diferentes posiciones religiosas de la audiencia del programa radiofónico Escuela para Todos que es transmitido todos los días a todo el territorio mesoamericano.

EI ICECU, a través de su programa radiofónico Escuela Para Todos (EPT), transmitido actualmente por más de ochenta emisoras a lo largo y ancho de la región de Mesoamérica, y del almanaque con el mismo nombre, ha forjado una importante audiencia en toda la región por más de medio siglo (19602012). Mediante el envío de cartas, propiciado por el mismo ICECU, esta audiencia ha tenido la oportunidad de dialogar con el Instituto, particularmente expresando dudas o comentarios relacionados con los contenidos transmitidos en el programa radiofónico y el almanaque Escuela Para Todos. Luego, los contenidos temáticos presentes en la correspondencia generan una agenda de tópicos que es retomada por el Instituto por medio de los programas radiales y del almanaque, proceso circular que propicia una importante dinámica de retroalimentación entre el Instituto y su audiencia. 
1. Recientemente, la UNESCO ha reconocido este trabajo de recopilación del ICECU como Patrimonio de la Humanidad.

Entrevista a la secretaria ejecutiva del ICECU, Ana Cristina Fernández, 17 de Mayo, 2010. UNED y Canal 15 del Sistema Universitario de Televisión.
Según el propio ICECU, en más de cuarenta y cinco años se han recibido y respondido cerca de 200000 cartas de toda Mesoamérica. La correspondencia que llega a los archivos de ICECU contiene preguntas y comentarios acerca de los ámbitos más diversos del saber humano. Además, el Instituto cuenta con un Centro de Documentación en el que alberga todas las cartas recibidas a lo largo de su historia; el cual representa un acervo de cultura intangible único ${ }^{1}$ en la región, disponible para ser estudiado desde diversas perspectivas: desde la antropología, la sociología, la filosofía, la teología, etc.

Justamente, una de las temáticas más sobresalientes en la correspondencia es la religiosa, al menos la que el Instituto califica como tal. Esta parte de la correspondencia es conservada en un archivo particular denominado Archivo Celeste. El archivo no se conserva de forma digital, de manera que durante los últimos meses se ha invertido buena parte del tiempo de la investigación en la digitalización del material; proceso que ha propiciado una mejor manipulación de los contenidos del archivo para detectar las potencialidades investigativas que ofrece el material, particularmente sobre un fenómeno tan complejo como es el religioso.

Valga hacer énfasis en el hecho de que el presente trabajo investigativo se enmarca dentro de un proyecto mayor. Sin embargo, se busca dar respuesta, aunque sea parcial, a una de las primeras interrogantes que surgieron durante la elaboración del proyecto: ¿Qué tipo de respuestas ofrece un instituto laico, como lo es el ICECU, a preguntas sobre religión?

Se trata de un tema que remite a preocupaciones profundas por el sentido y la existencia, a la vez que comporta diferentes modos de ver, percibir, concebir y creer; tan diversos como las personas que escriben, o bien, como los contextos culturales y socioeconómicos implicados. Cuestionamientos que obligan al ICECU a pronunciarse sobre tópicos complejos y, en este movimiento, a incursionar en el campo religioso mesoamericano, al lado de instituciones explícitamente religiosas como lo son las iglesias, por ejemplo. Esta "forzada" incursión permitió que la pregunta planteada como punto de partida de la investigación en el párrafo anterior adquiriera plena pertinencia y se planteara de la siguiente forma: ¿Responde ICECU a las cuestiones religiosas desde una postura inminentemente laica o si, por el contrario, reproduce alguna de las formas de religiosidad ya presentes en el campo religioso mesoamericano?

La teoría del campo religioso (Bourdieu, 2006) animó prácticamente la totalidad del proceso investigativo. Según esta teoría lo religioso puede entenderse como un campo objetivo en el que se configuran posiciones (agentes dominantes y dominados) a partir de la disputa por el capital propio de dicho campo, a saber: los bienes de salvación. 
Tanto las preguntas como las respuestas, pero sobre todo estas últimas, fueron analizadas a partir de los planteamientos de la teoría en mención. Las cartas escogidas para el análisis corresponden a aquella porción del Archivo Celeste que el Instituto cataloga bajo la etiqueta de "brujería y maleficios"; etiqueta que adelanta el contenido temático de la correspondencia abarcada. La escogencia de esta fracción del material fue producto de un conocimiento previo de la teoría de Bourdieu (2006) según la cual la brujería, como producto de la constante descalificación de los agentes religiosos dominantes, ocupa una posición subordinada dentro del campo religioso. Siguiendo esta lógica teórica, acompañada de una revisión preliminar del material, se consideró que las respuestas planteadas por el ICECU a las preguntas de este género, podían ser reveladoras respecto de la posición que ocupa el Instituto dentro del campo religioso mesoamericano.

La primera parte del presente escrito expone los rasgos esenciales de la teoría del campo religioso de Bourdieu (2006), y enfatiza particularmente en las posiciones que según el autor se configuran dentro del campo religioso, ya que componen la base sobre la cual se analizaron las respuestas brindadas por el Instituto. Un segundo apartado presenta algunos de los rasgos fundamentales del ICECU, en tanto institución educativa/cultural, y la forma en que incursionó dentro del campo religioso mesoamericano. El tercer apartado se centra en los aspectos más operativos y reveladores del ejercicio investigativo, como lo son los resultados desprendidos del análisis de las respuestas brindadas por el Instituto. Finaliza el documento con un apartado de conclusiones que arroja una nueva serie de preguntas y tareas pendientes, tanto para efectos del proyecto mayor en el cual se enmarca este ejercicio particular, como para efectos del quehacer propio del ICECU.

\section{Una aproximación a la teoría del campo religioso de Pierre Bourdieu}

El campo religioso comparte las propiedades de cualquier campo objetivo, tal como lo caracteriza Bourdieu (2002); dentro de este existe una especie particular de capital, una lucha entre diferentes agentes por la apropiación de dicho capital y ciertos habitus que se generan a partir de tales dinámicas.

Al igual que en cualquier otro campo, los agentes o posiciones que se configuran dentro del campo religioso son producto de la propia dinámica de lucha por la apropiación del capital particular; precisamente las posiciones aluden al lugar (dominante o dominado) que ocupan los agentes como resultado del capital acumulado a partir de las diferentes luchas que se libran dentro del campo. Estas posiciones son de carácter objetivo, en tanto resultado de un proceso socio-histórico de larga data y, en virtud de ello, son relativamente estructuradas. 
Asimismo, la posición que ocupa cada agente dentro del campo, en este caso el religioso, solamente adquiere sentido en relación con la ubicación de los demás agentes, lo cual responde al principio que sostiene que lo real es relacional (Bourdieu, 1997, p. 13). Desde las distintas posiciones se condicionan (producen y reproducen) también, como parte del mismo proceso, habitus particulares; es decir, diversas formas de percibir, conocer, valorar y actuar que diferencian a quienes confluyen en el campo.

El capital específico por el que confluyen y compiten los diferentes agentes dentro del campo religioso son los denominados bienes de salvación (Bourdieu, 2006), los cuales giran en torno a la administración legítima de lo sagrado y de las técnicas de sanación del alma y del cuerpo. El campo específicamente religioso nace, según Bourdieu (2006), como resultado de un proceso de complejización de las sociedades; el cual estuvo asociado al origen y desarrollo de las ciudades, a las trasformaciones socio-económicas y tecnológicas correlativas y, por supuesto, al progreso de la división social del trabajo, el cual permitió la creciente separación del trabajo material y del trabajo intelectual. El conjunto de transformaciones generó las condiciones para el surgimiento de un cuerpo de especialistas (sacerdotes) interesado en la "sistematización y moralización de las prácticas y creencias míticas; proceso que provocó la transformación del mito, en tanto (cuasi) sistema objetivamente sistemático, en ideología religiosa, entendida como (cuasi) sistema expresamente sistematizado" (Bourdieu, 2006, p. 40).

La tesis anterior también es sustentada por autores como Berger y Luckman (1979), quienes argumentan que el pensamiento teológico únicamente se diferencia del mitológico por su mayor grado de sistematización teórica; operación realizada, según estos autores, por élites de especialistas que se encargaron de convertir saberes de dominio social común (los mitos) en saberes exclusivos y, por ende, excluyentes.

Bajo este panorama se configura la primera de las disputas por el capital específicamente religioso. El paso del mito a la ideología religiosa, o de la mitología a la teología, detonó un proceso de expropiación de saberes de dominio común; proceso que progresivamente devino en la consolidación de un cuerpo o grupo especializado en saberes religiosos. Aparece así el capital específicamente religioso, el cual pasa a ser poseído de manera cuasi monopólica por este cuerpo de especialistas. En el mismo proceso, una porción importante de personas quedan tanto desposeídas del capital religioso y de la gestión legítima de los bienes religiosos; personas que, como resultado de esta desposesión, se configuran como un grupo dependiente de la gestión religiosa del cuerpo de especialistas, único capaz de garantizarles algún tipo de acceso a los bienes de salvación. Al respecto señala Bourdieu (2006):

(...) la constitución de un campo religioso es correlativa de la desposesión objetiva de los que están excluidos de él y que se en- 
cuentran constituidos por eso mismo en tanto que laicos (o profanos en el doble sentido del término) desposeídos del capital religioso (como trabajo simbólico acumulado) y que reconocen la legitimidad de esta desposesión por el sólo hecho de que la desconocen como tal (pp. 42-43).

En estos términos, laico es toda aquella persona desposeída del capital religioso que, no obstante, sigue interesada en bienes de este tipo y para acceder a ellos depende de la intermediación de la clase sacerdotal. Así, la oposición cuerpo sacerdotal/laicado se erige como la más importante oposición dentro del campo religioso, mas no la única.

Además de esta oposición elemental que opera dentro del campo religioso entre cuerpo sacerdotal y laicado, Bourdieu (2006), siguiendo a Max Weber (1997), señala la existencia de otra disputa, esta vez entre expertos, por el monopolio (gestión, producción y reproducción) legítimo de los bienes de salvación. Dos agentes entran en la pugna por este capital, a saber: el brujo o mago y el profeta; los cuales se corresponden - a modo de tipos ideales con demandas y necesidades religiosas de ciertas fracciones del laicado que no encuentran adecuada satisfacción a través de la mediación religiosa sacerdotal; demandas y necesidades que se encuentran ancladas en los modos de vida (ethos) - o condiciones de existencia - particulares de estas fracciones.

Es necesario recordar que la monopolización del campo religioso por parte del agente sacerdotal rara vez llega a ser completa y que se trata más bien de una tendencia posibilitada por condiciones histórico-sociales (externas al campo religioso) y por dinámicas (relaciones de fuerza entre agentes) propias del campo religioso. Resulta prácticamente imposible que un modo religioso particular, como lo es el sacerdotal, sea capaz de imponerse como la única expresión religiosa posible dentro de una sociedad o cultura específicas, sobre todo cuando se tiene presente que en cualquier sociedad coexisten fracciones muy variadas - en términos culturales y de clase - de laicos, así como de intereses y necesidades religiosas. Es bajo un panorama tal que adquiere sentido hablar de agentes proféticos y agentes mágicos como competidores directos de los agentes sacerdotales.

Un agente profético es un empresario independiente que disputa al agente sacerdotal la gestión legítima de los bienes de salvación, para lo cual produce y distribuye bienes religiosos relativamente novedosos tendientes a desvalorizar los producidos por la clase sacerdotal, es decir, los bienes religiosos preponderantes dentro del campo. Su éxito depende, precisamente, de su capacidad de producir bienes de salvación acordes con los intereses religio- 
sos de fracciones del laicado insatisfechas con los bienes religiosos sacerdotales.

La designación de profético, dentro de este esquema, puede ser atribuida a una institución que, siendo de reciente incursión en un campo religioso particular, produce y distribuye bienes religiosos relativamente diferentes a los producidos por la institución tradicional y dominante dentro de este campo religioso. Piénsese, por ejemplo, en el campo religioso latinoamericano, en donde la incursión de iglesias cristianas de corte pentecostal ha socavado el cuasi monopolio religioso - al menos institucional - que la Iglesia Católica ostentó en la región por casi medio milenio (Bastian, 1997); en definitiva de trata de una oferta religiosa institucional que ha sido capaz de producir bienes de salvación que han gozado de una gran acogida entre buena parte del laicado latinoamericano. Ahora bien, la disputa e innovación profética también pueden presentarse dentro de una misma institución, ya que la clase sacerdotal tiende a ser heterogénea, y por tanto, susceptible a sufrir rupturas (Maduro, 1980).

La teología latinoamericana de la liberación es el ejemplo por antonomasia de un movimiento profético a lo interno de una institución religiosa (Iglesia Católica); aunque quizá su "éxito" ha sido más limitado que el alcanzado por las iglesias pentecostales. Ahora bien, en cualquiera de las dos formas proféticas (extra o inter institucional) la intención - no necesariamente consciente - de los agentes es subvertir el orden del campo religioso y cambiar la dinámica de este; la pretensión de todo agente profético es la de hacerse con el ejercicio legítimo del poder religioso (Bourdieu, 2006, p. 65), por tanto, con el control del campo religioso.

La competencia del agente mágico es completamente diferente, ya que este no pretende hacerse con el ejercicio legítimo del poder religioso, sino que "responde a demandas parciales e inmediatas [de parte de cierto sector del laicado]" (Bourdieu, 2006, p. 66). Bourdieu, solamente se refiere al mago o brujo como un empresario que opera al margen de cualquier institución religiosa, generalmente en la clandestinidad. Además, señala que las prácticas y creencias mágicas tienden a ser más frecuentes entre las clases populares; en condiciones de precariedad y apremio material tales como la pobreza y la enfermedad; de ahí que la oferta mágica sea - según Bourdieu - inminentemente una práctica orientada a la sanación del cuerpo y a la resolución de problemas de carácter económico. Aunque se trata de una concepción algo reductora - en términos culturales - del fenómeno mágico, la caracterización de Bourdieu permite entender que la magia no ha desaparecido y difícilmente vaya a hacerlo; esto en virtud de la función que las personas materialmente agobiadas le atribuyen.

Es comprensible ahora que Bourdieu (2006) utilice la metáfora del mercado para referirse a la dinámica propia del campo religioso, signada por la com- 
petencia entre agentes por satisfacer las demandas de las diferentes categorías de laicos; satisfacción en la que reside el poder y el capital religioso del que puedan disponer los diferentes agentes dentro del campo religioso. Un autor como Fierro (1979), refiriéndose a la diferencia entre religión clerical y popular, remarca la imposibilidad que representa para un agente sacerdotal, como la Iglesia Católica, lograr alcanzar todas las categorías de laicos en una determinada sociedad y señala que aún cuando fuese posible "su logro se vería fatal e inseparablemente afectado de importantes alteraciones en los resultados previstos y queridos" (Fierro, 1979, p. 71). Lo que significa que en la religión realmente vivida por el laicado muchas veces coexisten prácticas y creencias cuyas matrices no sólo son diferentes, sino que, desde el punto de vista de sus orígenes, son antagónicas; como lo sería, por citar un ejemplo, la común convivencia de la magia y el catolicismo.

No obstante, Bourdieu no concibe este mercado como un mercado libre (De la Torre, 2002), por el contrario, se encuentra condicionado por monopolios relativos y relaciones objetivas de fuerzas que hacen que la competencia entre los diferentes agentes se presente en condiciones desiguales. En el caso particular del campo religioso, la posición sacerdotal cuenta con la capacidad, por mayor poder (material, simbólico, político) para descalificar, deslegitimar y perseguir aquellas prácticas y creencias de índole mágica o profética que amenacen su posición dominante. Basta pensar, por ejemplo, en la experiencia histórica de la Iglesia Católica en Latinoamérica (Bastian, 1992); institución que ha tendido a condenar cualquier expresión (práctica, creencia) teológico-religiosa, mágica, o mítica ubicada fuera de los límites de su corpus doctrinario (cosmovisión, ideología, etcétera). Piénsese, por ejemplo, en la descalificación que dirige la Iglesia Católica - principalmente su jerarquía hacia los agentes proféticos institucionales que disputan la interpretación legítima del cristianismo, a los que caracteriza como sectas, no en el sentido sociológico (Weber, 1969), sino en una dirección inminentemente peyorativa, como movimientos heréticos y poco calificados en materia religiosa (Fierro, 1979).

La misma violencia ejerce el catolicismo contra los pueblos indígenas latinoamericanos, particularmente contra sus prácticas y creencias mítico-religiosas y contra sus cosmovisiones en general. Rojas (2002), refriéndose al contexto de las comunidades indígenas bribis en Costa Rica, señala la existencia de una dinámica de competencia entre la Iglesia Católica y lo que él denomina la religiosidad tradicional indígena, en la que el catolicismo, para reforzar su presencia en la región, ataca y desvaloriza el conocimiento tradicional indígena: "las prácticas curativas, los rituales y las creencias en torno a la muerte, el nacimiento y el matrimonio"; al tiempo que deslegitima a los "chamanes y a otras figuras importantes en las prácticas indígenas” (Rojas, 2002, p. 42).

Por supuesto, las prácticas y creencias mágicas no escapan a la descalificación de parte del catolicismo, por el contrario, históricamente han sido las for- 
mas "religiosas" que más han padecido la persecución católica (Quaife, 1989). Recuérdese, por ejemplo, la cacería de "brujas" llevada a cabo por la Iglesia Católica a través de la Santa Inquisición, época en la que se consideraba a la magia y a la brujería como prácticas y creencias diabólicas, por ende, contrarias a Dios y a la religión (Quaife, 1989). De la misma forma, el catecismo católico vigente concibe la magia y la brujería como una forma de superstición, o de desviación del culto debido al Dios verdadero, que atenta contra el mandato divino: no tendrás otro Dios fuera de mí (Vaticano, 2005); lo cual hace la sanción más que patente.

Debido al tema del presente artículo, el cual analiza comunicaciones relacionadas con magia y brujería, resulta evidente que la audiencia del ICECU pregunta sobre y/o desde la parcela mágica del campo religioso, lo cual no excluye que las interrogantes contengan mediaciones religiosas de tipo sacerdotal o profético; no obstante, lo que es innegable es que la pregunta misma sobre la magia sitúa a esta dentro del espectro de opciones "religiosas" presentes en el campo religioso mesoamericano, así como dentro del universo cultural mesoamericano visto en términos globales. Consecuentemente, las respuestas que brinda el ICECU a este tipo de preguntas constituyen un buen acercamiento para determinar el carácter (ethos, particularidad) de la respuesta brindada por el Instituto, lo cual permitirá, a su vez, identificar de qué forma se posiciona la institución dentro del campo religioso mesoamericano.

Interesante resulta el hecho que la audiencia del ICECU, que forma parte del laicado mesoamericano, recurra a un Instituto de carácter laico para cuestionar sobre temas religiosos que normalmente son competencia de instituciones o agentes especializados, como lo son las iglesias, los sacerdotes, los pastores, los magos, etc.; lo cual podría suponer que existen demandas religiosas de cierto sector del laicado mesoamericano que no están encontrando satisfacción adecuada en el seno de las ofertas institucionales específicamente religiosas, de ahí el interés por identificar de qué forma participa el Instituto dentro del campo religioso mesoamericano.

\section{Experiencia ICECU: la incursión de una institución educativa/cultural laica en el campo religioso mesoamericano}

EI ICECU - según se señaló líneas arriba - no nace con una misión de carácter explícitamente religioso, sino que surge con la "intención de dar alcance - cuantitativo y cualitativo - al déficit de la educación formal en la región centroamericana" (Malavassi, 1978, p. 95). Ahora bien, las materias que formarían parte de este interés educativo/cultural no fueron prefijadas con anterioridad a la creación del Instituto, sino que estas se fueron determinando una vez desarrollado este, a partir de la investigación y de la interacción con su audiencia, tal como lo señala el Artículo $4^{\circ}$ de la Ley de Creación del Instituto, 
que estipula como sus funciones más importantes: "1) Investigar la condición cultural de los grandes sectores populares; y 2) Determinar aquellas ramas del conocimiento humano, en que deban ilustrarse esos sectores populares."

Lo religioso devino así en tema de interés para el ICECU gracias a las inquietudes que su audiencia, desde muy temprano, empezó a mostrar sobre el tema, y no como resultado de un trabajo investigativo realizado por el Instituto. Valga resaltar que las cartas recibidas por el ICECU de parte de su audiencia constituyen el insumo fundamental sobre el que se levanta la labor del Instituto, al punto que Malavassi (1978) propone la hipótesis de que "en el momento mismo que no lleguen más cartas enviadas por los usuarios de los medios del ICECU, éste ya no tendrá ninguna tarea que realizar" (p. 333). Es la correspondencia y los tópicos albergados en ella, lo que alimenta el contenido temático tanto de los programas radiales como del almanaque anual que produce el Instituto. A través del intercambio, la audiencia pone de manifiesto sus dudas, necesidades e intereses, es decir, se expone a la institución y establece una relación comunicativa con ella. Así es como se instaló el tema religioso en la preocupación y el quehacer del Instituto.

Por las razones precitadas, el ICECU ingresó, como institución educativa/cultural, al campo religioso mesoamericano. Se sostiene la hipótesis de que esta incursión provocó que el Instituto entrara a "jugar" en la dinámica propia del campo religioso, ya sea adhiriendo y reproduciendo algunas de las posiciones ya configuradas dentro de este, o bien, desde una postura completamente novedosa y alternativa a ellas, tal como se podría esperar de una institución que, según el Artículo $2^{\circ}$ de su Ley de Creación (Asamblea Legislativa, 2011), no tiene afiliación religiosa alguna.

En la investigación se catalogó al ICECU como una institución de carácter educativo/cultural, siguiendo el Artículo $4^{\circ}$ de la Ley de Creación del Instituto según el cual el Instituto se creó "para difundir la cultura general a los adolescentes y adultos de todas las capas sociales, pero especialmente a aquéllos que hayan tenido poca o ninguna posibilidad de beneficiarse con los sistemas reguladores de educación" (Asamblea Legislativa, 2011, p. 6).

Una institución de esta naturaleza, posee una vocación explicita de influir de alguna manera en la vida de millones de personas, en este caso brindándoles "cultura general". Implícitamente, no obstante, esta loable vocación comporta la inculcación de habitus particulares en las personas a las que alcanza la labor del Instituto. Esta naturaleza institucional ineluctablemente posiciona al Instituto en una relación de poder con su audiencia, en la cual él ocupa el lugar dominante. Téngase presente que la población a la que se dirige el ICECU pertenece a las clases o capas subalternas de la región mesoamericana, sobre las cuales han recaído los procesos sistemáticos de exclusión de todo tipo, además de la exclusión de la educación formal. 
No obstante la mentada intención educativa del Instituto, Malavassi (1978) sostiene que la labor de este no es de carácter pedagógico ni andragógico sino que se trata de labor inminentemente comunicativa, en los siguientes términos:

(...) el ICECU se enorgullece de decir que se ocupa de comunicación: de comunicarse con los demás, de interesarse especialmente por aquellas personas privadas de la educación sistemática; de dar información objetiva y neutral, tanto al tenor de sus postulados éticos como en razón de su interpretación de lo que es la cultura general: satisfacer el deseo de saber de quien lo tiene y lo indica así al ICECU y está en la resolución de mantener diálogo con la institución; contribuir a dar ilustración a quien expresamente la pide (p. 446).

Aunque efectivamente esta voluntad comunicativa está presente en la labor y principios del Instituto, no es posible conceder validez a la opinión de Malavassi. La tarea del ICECU, no obstante su vocación anti-autoritaria y de respeto de la dignidad humana, implica una pedagogía y, como toda acción pedagógica (Bourdieu y Passeron, 1998), también algún grado de violencia simbólica ya que "Toda acción pedagógica (AP) es objetivamente una violencia simbólica en tanto imposición, por un poder arbitrario, de una arbitrariedad cultural" (p. 45).

Lo anterior es patente en el manifiesto interés de parte del Instituto de ilustrar "intelectualmente" a la masa campesina y suburbana (Malavassi, 1978), donde ilustrar es iluminar, instruir, o incluso civilizar, por lo que enseguida salta la duda respecto de cómo sería posible aplicar esta acción en un ámbito como el religioso. Solamente suponiendo la existencia de formas de vivir la religiosidad más "exactas" o "correctas" que otras, sería posible llevar a cabo una tarea tal de ilustración religiosa, lo cual constituiría un craso error dentro de un contexto como el mesoamericano, profundamente diverso y desigual en términos culturales y socioeconómicos (de clase), en el que coexisten distintas maneras de vivir y pensar lo religioso. Ignorar este contexto conduciría a formas explicitas de violencia simbólica, situación que el ICECU pretende evitar cuando se impone como imperativo ético "investigar la condición cultural de los grandes sectores populares" de Mesoamérica. Solamente para una institución específicamente religiosa, como lo puede ser una iglesia, podría tener sentido la pretensión de "ilustrar", en el sentido de sacar de la ignorancia religiosa, a un laicado particular, mas no tendría por que ser del interés de un Instituto educativo/cultural de naturaleza laica. Principio que el mismo 
ICECU se fija cuando establece que "sus labores no se regirán por fijación religiosa ni por ideología política” (Asamblea Legislativa, 2011, p. 16).

Por tanto, el asunto señalado no es de menor importancia, ni para efectos del presente escrito ni para la labor del Instituto, el cual genuinamente desea establecer un adecuado acercamiento comunicativo con su audiencia. Un acercamiento que, en opinión de Fajardo (2010), tiene como propósito llevar a cabo:

(...) una acción de traducción cultural, que asumiendo el modo

de pensar campesino, edificara un "inter-logos" de significados

entre ambos mundos [el científico y el mítico] culturales, donde

las ciencias del saber se dieran cita para satisfacer en principio

la sed de conocimiento del campesino (p.10).

Bajo esta premisa filosófica cobra especial significado el tema desarrollado, ya que lo religioso es particularmente susceptible de ser vivido desde diferentes logos y lugares culturales, sobre todo en una región como la mesoamericana en la que coexisten, aunque no necesariamente conviven, formas míticas y/o religiosas cuya ascendencia se remonta a los pueblos originarios, formas religiosas y/o míticas de matriz occidental (judeo-cristianas), y, por supuesto, manifestaciones míticas y/o religiosas de procedencia africana. En consecuencia, las respuestas que ofrece el ICECU a preguntas relacionadas con un fenómeno como el mágico constituyen un buen indicador para determinar si efectivamente el Instituto logra una "traducción cultural" adecuada; traducción en la que radicaría su éxito comunicativo.

\section{Respuesta del ICECU: entre la reproducción de la religiosidad sacerdo- tal y el cientificismo}

Para determinar el carácter de la respuesta brindada por el ICECU a las preguntas sobre magia y brujería, se procedió de la siguiente forma: 1) se digitalizaron y agruparon todas las cartas concernientes a estos tópicos, así como sus respectivas respuestas; 2) se separaron las preguntas de las respuestas con el fin de examinarlas con independencia y posteriormente unirlas para su análisis conjunto ${ }^{2} ; 3$ ) cada una de las preguntas y de las respuestas constituyó una unidad de análisis particular; y 4) a partir del análisis de las unidades se identificaron tendencias en el patrón de respuesta del ICECU que después fueron agrupadas y analizadas a partir de la teoría del campo religioso de Bourdieu, que hermenéuticamente resultó adecuada para este propósito.

2.En el presente artículo las preguntas solamente se utilizan de manera ilustrativa, o bien, descriptiva; con el único fin de hacer más comprensibles las respuestas y la relación pregunta/respuesta. Un análisis profundo de las preguntas será tarea de un segundo artículo. 
Se encontraron un total de setenta y siete preguntas, e igual número de respuestas, relacionadas con magia y brujería, las cuales constituyeron el material sobre el que se levantó el análisis. Se trata de preguntas recibidas por el Instituto desde los años sesenta hasta el segundo lustro de la primera década del 2000; período que se mantuvo para efectos del análisis, ya que no se encontraron diferencias significativas, sobre todo en el ámbito de las respuestas, entre los contenidos de las cartas más antiguas y los de las más recientes.

En el ámbito de las respuestas, objeto de interés del presente artículo, se hallaron dos tendencias de matriz diferente pero que - como se verá - poseen algunos elementos en común, particularmente su talante descalificador de las prácticas y creencias mágicas: una reproductora de la posición religiosa sacerdotal y otra de índole cientificista ilustrada. Por posición religiosa sacerdotal se entenderá, siguiendo a Bourdieu, a toda aquella forma de religiosidad producida por los grupos, instituciones o individuos, en suma, agentes que ocupan la posición dominante dentro de un campo religioso particular. En este caso se trata de religiosidad cristiana, católica y fundamentalmente clerical. La religión históricamente dominante en mesoamérica es la cristiana, particularmente en su versión católica apostólica romana; institución en la cual domina el clero o "cuerpo de administradores religiosos -obispos, sacerdotes y pastores- y la clerecía ideológica -expertos doctrinales, teólogos y maestros-" (Fierro, 1979, p. 69).

En Mesoamérica el cristianismo es sacerdotal respecto de otras religiones y/o cosmovisiones míticas presentes en la región. Al mismo tiempo, el catolicismo es sacerdotal respecto de otras denominaciones cristianas. Y por último, dentro del catolicismo, sacerdotal es aquella casta que domina dentro de la institución: clero y clerecía ideológica; casta que tiende a imponer habitus particulares (sacerdotales) en el laicado católico.

Por otro lado, por postura cientificista ilustrada se comprenderá: aquella ideología que postula al saber científico como única forma válida de conocimiento; superioridad que estaría justificada en el éxito de los resultados arrojados por la ciencia contemporánea (Diéguez, 1993), en términos de exactitud y veracidad. Mientras que el carácter ilustrado reside en la acción de transmitir esta ideología o convicción a todas aquellas personas no-ilustradas en materia científica.

La primera de las tendencias es patente en treinta y tres de las respuestas ofrecidas por el ICECU, casi $43 \%$ del total. Por este motivo los ejemplos que se ofrecerán, si bien representan apenas una fracción del material, serán suficientes para exponer la posición reproductora de una religiosidad de tipo sacerdotal por parte del Instituto. La religiosidad sacerdotal es - tendencialmente - la forma de religiosidad dominante dentro del campo religioso, sobre todo en aquellas sociedades en las cuales el cristianismo, particularmente en 
su versión católica, es la religión históricamente dominante, como es el caso de las sociedades latinoamericanas en general.

La posición sacerdotal, en tanto posición dominante dentro del campo religioso, cuenta - o al menos así lo pretende - con el monopolio legítimo de los bienes de salvación, y por ende, desde ella se decide sobre las formas legítimas de vivir la religiosidad y se sanciona a todas aquellas formas consideradas ilegítimas, a las cuales se les condena fundamentalmente por el hecho de que su existencia pone en riesgo el dominio ostentado por el cuerpo sacerdotal (católico). La respuesta a una pregunta emitida por un hombre guatemalteco, en el año 1972, ilustra este punto con claridad:

Pregunta: ¿Quiénes y cuántos hicieron los libritos que usan los brujos o sea lo que le dicen oráculo y por qué tiene escritas allí en el libro unos versículos de la Biblia?

Respuesta: La brujería es muy antigua. Es muy posible que muchos escritos sobre brujería fueran recogidos y pasados de unas personas a otras durante siglos.

Por otra parte, como usted nos dice, dentro de la brujería es común oír el nombre de religiosos cristianos pero no porque la religión cristiana este de acuerdo con la brujería y con quienes la practican.

Nos han dicho varios sacerdotes que las personas que practican la brujería se valen de la falta de conocimientos religiosos y la falta de fe que tienen muchas personas, y que por esa razón es que usan trozos de la Biblia y nombres de santos, para hacer creer que lo que ellos hacen está dentro de la religión y así engañan a la gente.

La respuesta comporta un claro posicionamiento reproductor de una religión de tipo sacerdotal, incluso hace referencia explícita a un tipo de agentes especializados: es la opinión de sacerdotes católicos que, de oficio, ven en la brujería el resultado de la ignorancia religiosa y de la falta de fe de parte quienes la creen y practican. Esta respuesta caracteriza a los agentes que ofrecen bienes mágicos como simples embusteros y manipuladores que se 
aprovechan de la falta de erudición teológico/religiosa de algunas personas, concepción con la cual se deslegitima tanto a los agentes mágicos como a quienes creen en la magia, o bien, practican algún tipo de sincretismo. El valor de esta opinión tiene pleno sentido en el seno de una iglesia particular pero no es capaz de relativizarse lo suficientemente como para entender, y aceptar, que en la cultura popular la religión y la magia muchas veces aparezcan fundidas y que "ahí" no necesariamente se debe achacar de "ignorancia religiosa" o "falta de fe": la lectura de que el origen de las prácticas y creencias mágicas solo denota pura negatividad - y culpabilización - impide un análisis riguroso y cuidadoso de esas experiencias y de quienes suscriban cierta confianza en las mismas.

Esta postura sacerdotal, deslegitimadora de las prácticas y creencias de carácter mágico, se encuentra con nítida claridad en la respuesta a una pregunta formulada por un hombre hondureño en el año 1988:

Pregunta: Creen ustedes en gente que haga medicinas naturales y sobrenaturales. Curar una casa para quitar la mala suerte, yo no creo ni dejo de creer, pues la Biblia dice que existe la brujería, pero también habla en contra de ella, pero a veces uno tiene mala suerte, ¿a qué se debe?

Respuesta: La Biblia y nuestra religión cristiana prohíben la brujería. Una persona puede esperar en su vida cosas como la buena suerte, una buena cosecha o buena salud. Pero también esa persona puede sufrir por enfermedades, por la muerte de familiares, por accidentes, por malas cosechas y las demás cosas que producen angustia y dolor. Todas estas cosas son naturales en la vida y a cualquier persona le pueden pasar, no tienen nada que ver con brujería.

La alusión a la Biblia y a "nuestra religión cristiana" es muestra fehaciente de la postura militantemente religiosa del ICECU, la cual se corrobora en el resto de las respuestas a través de expresiones como las siguientes: [esperamos que] con el apoyo de la fe religiosa de cada persona, la creencia en la hechicería desaparezca algún día (respuesta a una pregunta procedente de Guatemala en 1973); [...] verdaderamente estas cosas [capacidad de convertirse en un animal por medio de la brujería] no suceden en la realidad. 
Pues una persona no puede cambiar las cualidades que hemos recibido de Dios, nuestro Creador (respuesta a una pregunta procedente de Nicaragua en 1980); [...] la fe en Dios y en su poder es lo que hace que quien crea tener un maleficio salga bien de esa creencia [...] (respuesta a una pregunta procedente de Costa Rica en 1985); [...] por más que una persona quiera asustar a los demás con malos deseos, la mejor defensa es tener fe en el amor infinito de Dios [...] (respuesta a una pregunta procedente de Guatemala en 2006).

En estos ejemplos, Dios y la fe en él son presentados como absolutamente verdaderos e inmensamente poderosos, en contraste con la magia (bujería, hechicería, etcétera) que más bien es mostrada como poco probable e infinitamente limitada ante el poder de Dios y de la fe. La magia se caracteriza de esta forma, o bien como religión inferior, o bien como anti-religión. El fundamento de esta caracterización reside en la oposición entre lo sagrado y lo profano: la religión (de tipo sacerdotal) ostenta el monopolio de la manipulación de lo sagrado, por ende, todo intento de manipulación de lo sagrado al margen de la religión, es decir, como manipulación profana o profanadora, será catalogado como magia.

En ese sentido, la práctica y el discurso sacerdotal se avocarán a la supresión simbólica de todas aquellas prácticas y creencias que amenacen su dominio dentro del campo religioso. Así es como el ICECU reproduce, sin necesariamente tener conciencia de ello, el tipo de religiosidad dominante dentro del campo religioso mesoamericano, toda vez que contribuye a la sanción de aquellas prácticas y creencias que pretenden manipular los bienes de salvación al margen de instituciones legítimas para tal efecto.

La sanción de cuño sacerdotal se termina de hacer patente a través de la caracterización negativa de las personas que adhieren prácticas y creencias mágicas, especialmente de aquellos agentes mágicos: magos(as), brujos(as), hechiceros(as), entre otros. La tendencia se encuentra en treinta de las setenta y siete respuestas, lo que representa $39 \%$ del total. En cuanto a los agentes se les concibe como: personas mal intencionadas que sólo tratan de hacer mal al prójimo (respuesta a una pregunta procedente de Costa Rica en 1965); personas que usan la sugestión para curar (respuesta a una pregunta procedente de Costa Rica en 1966); gentes envidiosas y malas cristianas (respuesta a una pregunta procedente de Costa Rica en 1973); personas de malos sentimientos que se dedican a hacer hechicerías (respuesta a una pregunta procedente de Nicaragua en 1975); personas que han creído encontrar en el mal la razón de su vida (respuesta a una pregunta procedente de Nicaragua en 1977); gente [que] lo que trata de hacer es estafar a los demás (respuesta a una pregunta proveniente de Guatemala en 1982); gente sin escrúpulos que se aprovecha del dolor ajeno para ganar dinero (respuesta a una pregunta procedente de Honduras en 2009); etcétera. 
Los calificativos hallados en los cuestionamientos anteriores hacen patente un prejuicio sacerdotal arraigado en el sentido común, ya que aunque no necesariamente sean todos falsos, tampoco podrían ser siempre válidos. Una carecterización de las prácticas mágicas y sus derivados debería fundamentarse en una investigación sistemática que sea más que la simple reproducción de la visión religiosa de los agentes que confluyen en el campo religioso, lo cual no impide que se pueda y deba tomar en cuenta la opinión de estos pero que sin duda no se agota en ella. En este caso particular, ICECU no sólo responde preguntas sobre religión, sino que también responde a ellas religiosamente, no desde una investigación basada en principios laicos.

La caracterización que hace el Instituto de quienes creen en la magia y sus derivados será ofrecida después de la exposición de la segunda tendencia identificada en las respuestas brindadas por el ICECU, la cual se encuentra en treinta y cuatro de las respuestas ( $44 \%$ del total) y que se ha identificado como de matriz cientificista ilustrada. Esta postura concibe las prácticas y creencias de carácter mágico como llanas supersticiones, las cuales tendrían su sustento en la ignorancia, por ende, su única posibilidad de incidencia residiría en la sugestión, tal como lo ilustra la siguiente respuesta a una pregunta enviada por un nicaragüense en el año 1967:

Pregunta: ¿Se puede matar a un individuo mentalmente?

Respuesta: Hay pueblos, por ejemplo en África, en donde creen mucho en el gran poder de sus brujos y hechiceros. Se ha comprobado que han sucedido casos como este: a un hombre del pueblo, lo ha maldecido el hechicero, el hombre que sabe eso está tan sugestionado, tan seguro de que está condenado a morir, que se va a la selva a morir. $Y$ se muere de veras, sin tener ninguna enfermedad. Se puede decir que el brujo mató al hombre mentalmente. Pero eso sucede solamente porque el hombre se dejó sugestionar por el brujo.

De esta forma ICECU niega cualquier poder "en sí" de las prácticas mágicas $y$, en cambio, señala que el poder de estas reside en su capacidad de sugestionar a las personas ya de por sí predispuestas para tal efecto. Juicio que tiende a la psicologización del fenómeno (lo cual simplifica un fenómeno complejo). 
En los siguientes fragmentos de respuesta queda manifiesto el mismo talante: "[...] la brujería no tiene poder para hacer mal a las personas ni tampoco para curar a los enfermos. Lo que sucede muchas veces es que las personas se dejan impresionar [...]" (respuesta a una pregunta proveniente de Guatemala en 1974); "[...] a medida que la ciencia ha progresado se ha descubierto que la brujería no tiene poder para hacerle mal a los demás" (respuesta a una pregunta proveniente de Panamá en 1974); "[...] brujería o superstición, (...) este tipo de cosas suelen tener creencias que van en contra de los principios de la ciencia" (respuesta a una pregunta proveniente de Costa Rica en 2010).

Los dos últimos fragmentos de respuesta reafirman la concepción cientificista que alberga y promueve el ICECU respecto de las prácticas mágicas y sus derivados, según la cual la falsedad de estas prácticas y creencias ha sido demostrada por la ciencia, justamente porque no se basan en los principios científicos: comprobación empírica y primacía de la razón. De esta forma, la magia es concebida - por el ICECU - como creencia arcaica y falaz que retrocede (demuestra su "falsedad") a medida que la ciencia avanza.

Es mediante estos ejemplos que se manifiesta el carácter ilustrado de la segunda tendencia mencionada. El Instituto se ha dado a la tarea de ilustrar científicamente a aquella porción de su audiencia que, a través de sus preguntas y comentarios, concede existencia y algún grado de eficacia (poder) a la magia, lo cual tendría su correlato en la ignorancia respecto de la ciencia en la que vive buena parte de "la masa campesina y suburbana" de la región mesoamericana. Una tarea tal conlleva un proceso de marcada violencia simbólica, ya que responder de manera cientificista no equivale a responder científicamente. La primera postura alberga y defiende una visión de mundo dominante, anclada en un proyecto de sociedad de raigambre europea, moderna y realista, por tanto, deviene en una postura normativa y sancionadora, incapaz de relativizarse en términos histórico/culturales. Una postura científica, en cambio, trataría de comprender las prácticas y creencias mágicas dentro del universo cultural en el que se despliegan y dentro del cual adquieren pleno significado; comprensión que puede apoyarse en disciplinas como la antropología, la sociología y la historia. De esto no se deriva que el ICECU deba tomar una postura apologista de la magia y sus derivados, en cambio, implica una actitud crítica basada en la comprensión y el respeto de las realidades históricas, sociales y, fundamentalmente, culturales mesoamericanas que subyacen a las visiones de mundo patentes en las cartas enviadas por la audiencia.

El sesgo cientificista y psicologicista en la concepción que el ICECU reproduce sobre la magia y sus derivados hace que el Instituto inconscientemente sancione como emocional y psicológicamente carentes a aquellas personas que conceden existencia y poder a estos fenómenos, tal como se refleja en los siguientes fragmentos de respuesta: "personas temerosas y faltas de do- 
3. Pregunta: "Estoy de acuerdo de sus programas de aconsejar a nuestros hermanos de no creer en las costumbres de los hechiceros porque sólo se valen de trucos y nada de cierto, de que si va a suceder todo eso, yo no lo creo porque todos los indígenas y nuestros antepasados esa es su creencia, yo creo que a alguna que le suceda es porque la crea, pero nosotros en nuestros últimos años no lo creemos porque el único que lo sabe nuestro destino es Dios

todopoderoso pues mi único consejo es que no le cuenten estas cosas a los niños, sólo así podemos quitar esas creencias que no vale la pena creer." minio propio son las que se engañan con eso" (respuesta a una pregunta proveniente de Costa Rica en 1965); "las brujerías en nada afectan a una persona que está segura y tranquila" (respuesta a una pregunta proveniente de Costa Rica en 1971); "si una persona se sugestiona creyendo que le han hecho un mal puede llegar a enfermarse y sentirse realmente mal" (respuesta a una pregunta proveniente de El Salvador en 1976); "el maleficio sólo puede afectar a las personas temerosas" (respuesta a una pregunta proveniente de Costa Rica en 1966). Al tratarse de personas que - en su mayoría - escriben preocupadas ante la posibilidad de estar padeciendo algún embrujo o maleficio, resulta comprensible que ICECU intente brindarles algún tipo de tranquilidad, sin embargo, la manera en la que lo hace no parte de una comprensión cabal del fenómeno.

Inmediatamente después de haber identificado las dos tendencias presentes en las repuestas brindadas por el ICECU a las preguntas sobre magia y sus derivados surge la incógnita respecto de la afinidad entre estas. La primera ubica al Instituto en una posición reproductora de la religión cristiana sacerdotal. Mientras que la segunda tendencia alberga una profunda confianza en la ciencia en tanto única forma válida de conocimiento (Habermas, 1982), donde sólo se admite como verdadero aquello que pasa por la comprobación empírica y la razón. No obstante esta flagrante incompatibilidad entre las tendencias, el Instituto logra compaginarlas conservando así cierta unidad doctrinal. Un cientificismo radical y consecuente relegaría tanto a la magia como a la religión al ámbito de la superstición (Dawkins, 2007), sin embargo, como se colige de la siguiente respuesta, este no es el caso del ICECU:

\section{Esperamos que con los avances de la medicina que actual-} mente permiten curar muchas enfermedades, y con el apoyo de la fe religiosa de cada persona, la creencia en la hechicería desaparezca algún día (Respuesta a una pregunta proveniente de Guatemala en 1973) ${ }^{3}$.

En esta respuesta los avances científicos (de la medicina) están reñidos con la hechicería pero no con la fe religiosa, con la cual podrían perfectamente complementarse; visión que reafirma el carácter expresamente sacerdotal de las respuestas ofrecidas por el Instituto. Defender la complementareidad entre la ciencia y la fe deviene en una estrategia legítima en un mundo cada vez más cientificista, pero no por ello deja de ser una estrategia. En este caso particular la noción de ciencia defendida por el ICECU no escapa al cientificismo, ni tampoco su noción de religión escapa a la religiosidad sacerdotal cristiana; visiones insuficientes para llevar a cabo la tarea de armonizar ciencia y religión. 


\section{Conclusión}

Se evidencia que las respuestas que ofrece el Instituto Centroamericano de Extensión de la Cultura (ICECU) a las preguntas realizadas por su audiencia sobre magia y brujería comportan un carácter sacerdotal. De esta forma el ICECU reproduce la visión religiosa del agente dominante dentro del campo religioso mesoamericano, a saber: el cristianismo católico. Este posicionamiento le hace compartir con el catolicismo dominante en la región la descalificación abierta de toda práctica y creencia de índole mágica; descalificación que recae tanto sobre los agentes (oferentes) mágicos, como sobre aquellas personas que conceden existencia o algún poder a estas prácticas y creencias.

La reprobación en mención se ve reforzada por una concepción cientificista ilustrada que confina a la magia y a la brujería al lugar de simple superstición. De manera tal que el Instituto renuncia, desde posturas ideológicas, a cualquier intento de comprensión de un fenómeno como lo es la presencia y supervivencia de la magia y la brujería en mesoamérica. Incomprensión que, según se ha sostenido en esta investigación, atenta contra la genuina voluntad dialógica que anima la labor del ICECU, por ende, contra la capacidad de alcanzar una comunicación efectiva con su audiencia. Las respuestas signadas por esta reducción reprobatoria del fenómeno provocan que el Instituto, con su capacidad educativo/tecnológica, contribuya a la inculcación, vía reproducción, de determinadas visiones de mundo dominantes o habitus en su audiencia, proceso que se puede calificar de violencia simbólica, "en tanto que imposición, por un poder arbitrario, de una arbitrariedad cultural" (Bourdieu y Passeron, 1996, p. 45).

Ahora bien, la labor del ICECU, tal y como lo reflejan sus principios, está inspirada en un auténtico deseo de lograr una comunicación efectiva y respetuosa con su audiencia, tratando de comprender las realidades, las necesidades y los lenguajes que subyacen a las preguntas realizadas por esta. Si en el caso del tratamiento de las preguntas sobre magia y brujería no ha conseguido este cometido, se debe fundamentalmente a la naturaleza compleja del fenómeno religioso.

Para el Instituto ha sido más sencillo y más seguro contestar a las preguntas analizadas desde una postura sacerdotal que arriesgar respuestas asentadas en otra matriz; por ejemplo, en investigaciones radicalmente laicas respecto de los contextos que soportan las prácticas y creencias mágicas en la región, las cuales contribuirían a alcanzar una comprensión cabal, no religiosa y no cientificista, del fenómeno. Investigaciones ya de por sí contempladas como parte intrínseca del quehacer del Instituto, pero que en este caso particular no se han realizado. 
Una noción que puede contribuir a dar soporte a esta tarea investigativa es la de relación comunicativa (Luckman, 2008), la cual remite a una preocupación anidada en la sociología del conocimiento que se pregunta por el origen y desarrollo de las interacciones de sentido. Las preguntas efectuadas por la audiencia del ICECU comportan una necesidad de disipar dudas o de confirmar certezas sobre tópicos particulares, necesidad que tiene su anclaje en el mundo cotidiano de quienes cuestionan, lo cual implica que para comprender las interrogantes es necesario remitirse a las condiciones primarias (cotidianas) en las que se sustentan. Desde esta perspectiva al ICECU le corresponde efectuar una labor científica de reconstrucción de los procesos sociales de primer orden, subyacentes a las dudas planteadas en las cartas, es decir, debe esforzarse por comprender adecuadamente el mundo desde el cual se formulan.

En este sentido, Fajardo (2007) propone la noción de interculturalidad como marco adecuado de comunicación entre el ICECU y su audiencia; esta noción alude a la capacidad de comprender, mediante una labor personal de traducción de códigos de sentido, las distintas significaciones vitales que pueden presentarse en la interpretación de hechos, tanto de persona a persona, como de un grupo humano respecto a otro (Fajardo, 2007). Capacidad que implica un diálogo y una voluntad de diálogo profundo entre las diferentes culturas, los diferentes ethos, los diferentes logos que coexisten en un espacio social determinado.

La aplicabilidad de la noción de interculturalidad es evidente en el caso mesoamericano, en donde la diversidad cultural es patente, aunque no siempre evidenciada. En relación con el tema religioso, un diálogo de este tipo implica, en primera instancia, un reconocimiento de la diversidad religiosa de la región, en la cual confluyen visiones típicamente religiosas pero también míticas, ancladas en cosmovisiones propias de los pueblos originarios, sólo por citar un ejemplo. En segundo lugar, envuelve una renuncia a cualquier pretensión etnocéntrica de verdad religiosa y a cualquier intento evangelizador o colonizador. Un acercamiento intercultural de este tipo podría provocar, por ejemplo, que el ICECU empiece a reconocer como legítimas, en tanto propias de un universo cultural particular, muchas de las prácticas y creencias que han caracterizado como supersticiones o contrarias a la religión. Prácticas y creencias que no sólo son propias de grupos socioculturales particulares, sino que también, y en virtud de lo anterior, se expresan desde logos muy diferentes a los típicamente occidentales.

Sin embargo, estas nociones deberán ser profundizadas y puestas a prueba en una nueva investigación dedicada al análisis de las preguntas realizadas por la audiencia. Ejercicio que servirá no sólo para ilustrar las preguntas, sino para ensayar modelos hermenéuticos que resulten adecuados para desentrañar el sentido profundo de sus contenidos. Trabajo que buscaría ser un aporte propositivo a la labor del ICECU y un buen insumo para la comprensión 
académica del fenómeno religioso mesoamericano, desde una perspectiva hasta ahora poco explorada en la región. Lo anterior enmarcado en un deseo más amplio de contribuir al descubrimiento de la mesoamérica culturalmente diversa, es decir, utilizando la expresión de Bonfil (1987), de la mesoamérica profunda.

\section{Bibliografía:}

Asamblea legislativa de la República de Costa Rica. (2011). Estudio sobre antecedentes normativos y gestión nacional e internacional del Instituto Centroamericano de Extensión de la Cultura (ICECU). San José, Costa Rica: Departamento de servicios técnicos. Recuperado el 25 de marzo del 2012

$$
\text { de }
$$
http://www.asamblea.go.cr/Centro_de_informacion/servicios_tecnicos/Doc uments/Consultas\%202011/CON-004-2011.pdf

Bastian, J.P. (1992). América Latina 1492-1992, conquista, resistencia y emancipación. Cuadernos Constitucionales México-Centroamérica, N. ${ }^{\circ} 4$.

Bastian, J.P. (1997). La mutación religiosa de América Latina: para una sociología del cambio social en la modernidad periférica. México: Fondo de Cultura Económica.

Berger, P. (1979). La construcción social de la realidad. Buenos Aires, Argentina: Editorial Amorrortu.

Bonfil, G. (1987). México profundo: una civilización negada. México: Editorial Grijalbo.

Bourdieu, P. (1997). Razones prácticas: sobre la teoría de la acción. Barcelona, España: Editorial Anagrama.

Bourdieu, P. (2002). Campo de poder, campo intelectual. Buenos Aires, Argentina: Editorial Montressor.

Bourdieu, P. (2006 [1971]). Génesis y estructura del campo religioso. Relaciones, 108, Otoño, Vol. XXVII, 29-83.

Bourdieu, P. y Passeron, J-C. (1998). La reproducción. Elementos para una teoría del sistema de enseñanza. México: Distribuciones Fontamara. 
Dawkins, R. (2007). El espejismo de Dios. Barcelona, España: Editorial Espasa Calpe.

De la Torre, R. (2002). El campo religioso, una herramienta de duda radical para combatir la creencia radical. Revista Universidad de Guadalajara, 24/Verano. Recuperado el 29 de marzo del 2012 de http://www.cge.udg.mx/revistaudg/rug24/bourdieu5.html

Diéguez, A. (1993). Cientificismo y modernidad: una discusión sobre el lugar de la ciencia. En J. Rubio Carracedo (ed.), El giro posmoderno, suplemento $\mathrm{n}^{\circ} 1$ de Philosophica Malacitana, 81-102.

Fajardo, J. (2007). Los fundamentos del proyecto 'Escuela Para Todos' en el área de Mesoamérica desde una lectura filosófica intercultural [versión electrónica]. Tesis de maestría, Universidad Alberto Hurtado.

Fajardo, J. (2010). Almanaque Escuela Para Todos: un valioso tesoro para la lecto- escritura en América Central. Ponencia presentada en el II Congreso Nacional de Lectura y Escritura de Panamá. Disponible en: http://es.scribd.com/doc/53584937/Ponencia-II-Congreso-Nacional-deLectura-y-Escritura-Mg-Fajardo-Salinas

Fierro, A. (1979). Sobre la religión: descripción y teoría. Madrid, España: Editorial Taurus.

Habermas, J. (1982). Conocimiento e interés. Madrid, España: Editorial Taurus.

Maduro, O. (1980). Religión y conflicto social. México: Centro de Estudios Ecuménicos.

Malavassi, G. (1978). Comprender lo comprensible. Tomo I. San José, Costa Rica: ICECU.

Quaife, G.R. (1989). Magia y maleficio. Las brujas y el fanatismo religioso. Barcelona, España: Editorial Crítica.

Rojas, D. (2002). El conflicto entre tradición y modernidad: constitución de la identidad cultural indígena Bribri. San José, Costa Rica: Cuaderno de ciencias sociales (FLACSO).

Vaticano. (2005). Compendio del Catecismo de la Iglesia Católica. Recuperado 24 de marzo del 2012 de http://www.vatican.va/archive/compendium_ccc/documents/archive_2005_ compendium-ccc_sp.html 
Weber, M. (1969). La ética protestante y el espíritu del capitalismo. Barcelona, España: Editorial Península.

Weber, M. (1997). Economía y sociedad. México: Fondo de Cultura Económica. 